\title{
Inhalt.
}

§ 1. Einleitung . . . . . . . . . . . . . . . . . . . . 1

Erster Teil.

Die haftpflichtigen Subjekte: Betriebsunternehmer und Betriebsbeamte.

§ 2. 1. Der Betriebsunternehmer . . . . . . . . . . . . . . 8

§ 3. 2. Die Betriebsbeamten . . . . . . . . . . . . . . . 17

a) Bevollmächtigte oder Repräsentanten.

1. Bevollmächtigte . . . . . . . . . . . . . 20

2. Repräsentanten . . . . . . . . . . . . . . 24

b) Betriebs- oder Arbeiteraufseher.

1. Betriebsaufseher . . . . . . . . . . . . . 27

2. Arbeiteraufseber . . . . . . . . . . 27

Zweiter Teil.

Die haftpflichtberechtigten Subjekte.

I. Die nach Maßgabe des Gewerbe-Unfallversicherungsgesetzes versicherten Personen.

A. Die unmittelbar auf Grund des Gesetzes versicherten Personen.

$\$ 4$ 1. Die unmittelbar auf Grund des Gesetzes versicherungspflichtigen Personen.

a) Arbeiter . . . . . . . . . . . . . . . . 30

b) Betriebsbeamte . . . . . . . . . . . . . 36

2. Die unmittelbar auf Grund des Gesetzes versicherungsberechtigten Personen. . . . . . 37 
§ 5. B. Die mittelbar auf Grund des Gesetzes versicherten Personen.

1. Die auf Grund des Statuts einer Berufsgenossenschaft versicherungspflichtigen Personen . . . . . 37

2. Die auf Grund des Statuts einer Berufsgenossensehaft versicherungsberechtigten Personen . . . . . 40

3. Die auf Grund des Statuts einer Berufsgenossenschaft versicherungsfähigen Personen . . . . . . . 40

8 6. II. Die Hinterbliebenen der nach MaBgabedes Gesetzes versicherten Personen . . . . . . . . . . . 44

a) Die Witwe . . . . . . . . . . . . . . 45

b) Kinder . . . . . . . . . . . . . . . . . . . . . . . 45

c) Verwandte der aufsteigenden Linie . . . . . . 51

d) Elternlose Enkel . . . . . . . . . . . . . . . 51

\section{Dritter Teil.}

Die Voraussetzungen des Anspruchs nach § 135 des GUVF.

\& 7. Allgemeines . . . . . . . . . . . . . . . . . . . 53

8 8. I. Vorsätzliche Herbeiführung des Betriebsunfalls 55

1. Betriebsunfall . . . . . . . . . . . . . . . 55

a) Unfall . . . . . . . . . . . . . . . . . . . 56

b) beim Betriebe . . . . . . . . . . . . . . 58

2. Vorsătzliche Herbeiführung desselben . . . . . . 59

a) Vorsatz . . . . . . . . . . . . . . . . 60

b) Herbeiführen . . . . . . . . . . . . . . . . . . 61

8 9. 3. Inwieweit schlieBt Vorsatz den ursächlichen $\mathrm{Zu}$ sammenhang mit dem Betriebe aus? . . . . . 62

a) Vorsatz des Verletzten . . . . . . . . . . . . 62

b) Vorsatz der Mitarbeiter . . . . . . . . . . . . . . 63

c) Vorsätzliche Herbeiführung des Unfalles durch den Betriebsunternehmer oder einen Betriebsbeamten. . . . . . . . . . . . . . . 64

\$ 10. II. Feststellung durch strafgerichtliches Urteil . . 66

1. Die Regel . . . . . . . . . . . . . . . . ${ }_{6}^{6} 6$

2. Die Ausnahme . . . . . . . . . . . . . . 68

3. Die Bedeutung der Feststellung durch strafgerichtliches Urteil . . . . . . . . . . . . . . 69

a) In formeller Beziehung . . . . . . . . . . . . . 69

b) In materieller Beziehung . . . . . . . . . . . 70

\$ 11. III. Eine bestimmte GröBe des Anspruchs . . . . 73 
Vierter Teil.

Der Umfang des Anspruchs und seine Berechnung.

§ 12. Allgemeines . . . . . . . . . . . . . . . . . . . 74

I. Der Minuendus:

1. Nach bürgerlichem Rechte . . . . . . . . . . 76

$\S 13$.

A. Schadensersatz im Falle der Körperverletzung . . . . . . . . . . . 76

1. Ersatz des materiellen Schadens . 77

2. Ersatz des immateriellen Schadens 78

3. Ersatz des Schadens für entgehende Dienste . . . . . . . . . 79

$\S 14$.

$\S 15$.

B. Schadensersatz im Falle der Tötung:

1. Für Beerdigungskosten . . . . . 80

2. Für entgehende Dienste . . . . 81

3. Für Entziehung des Rechts auf Unterhalt nach $\$ 844 \quad$. . . . 81

a) Allgemeine Grundsätze für die Schadensberechnung nach \$ 844 Abs. 2 . . . 81

b) Die Ansprüche der einzelnen Hinterbliebenen nach $\S 844$ Abs. 2:

1. Der Anspruch der Witwe bzw. des Witwers . . . . . . . . . . 83

2. Der Anspruch der Kinder . . . . 85

3. Der Anspruch der Verwandten der aufsteigenden Linie und der elternlosen Enkel . . . . . . . . . 87

\$16. Der Minuendus nach dem Haftpflichtgesetz . . . 88

\$ 17. 3. Der Minuendus nach dem Reichsstrafgesetzbuch . . 90 Die BuBe . . . . . . . . . . . . . . 90

§ 18. II. Der Subtrahendus:

1. Im Falle der Körperverletzung . . . . . . . . 93

2. Im Falle der Tötung . . . . . . . . . . . . . 97

\$ 19. III. Die Differenz und ihre Berechnung:

1. Im Falle der Körperverletzung . . . . . . . . 103 Der Anspruch:

a) auf Heilverfahren . . . . . . . . . 103

b) für Erwerbsfähigkeitsminderung . . . . 103

c) für Nachteile im Erwerb und Fortkommen 106

d) für entgehende Dienste . . . . . . . 106

e) für immateriellen Schaden . . . . . . . 106

f) für Sachschaden . . . . . . . . . . 106 
Seite

2. Im Falle der Tötung . . . . . . . . . . . . 107

Der Anspruch:

a) auf Sterbegeld und Beerdigungskosten . . 107

b) der Witwe . . . . . . . . . . . . 108

c) der Kinder . . . . . . . . . . . . . . . 109

d) der Verwandten der aufsteigenden Linie und der elternlosen Enkel . . . . 110

Fünfter Teil.

§ 20. Veränderung und Untergang des Anspruchs nach $\S 135$ GUVG.

1. Veränderung des Anspruchs . . . . . . . . . . . . 111

2. Untergang des Anspruchs . . . . . . . . . . . . . 113

a) Tod des Berechtigten. . . . . . . . . . . . . . . . . 113

b) Tod des Verpflichteten . . . . . . . . . . . . . . . . 113

c) Zeitablauf . . . . . . . . . . . . . . . . . . . . . . . 114

3. Verjährung der Ansprüche . . . . . . . . . . . . 11 ई

Sechster Teil.

$\S 21$. Die juristische Natur des Anspruchs . . . . . . . . . 116

S .2. Schlußergebnis . . . . . . . . . . . . . . . . . . . . 118 